\title{
The Promise of the New Educational Strategy for Curriculum Development (SPICES) Model on the Development of Students' Clinical Reasoning Ability. A Comparative Cross-Sectional Study
}

\author{
Equlinet Misganaw ${ }^{\prime}$ \\ Tegbar Yigzaw ${ }^{2}$ \\ Robel Tezera ${ }^{3}$ \\ Awoke Gelitew (iD) \\ Shewatatek Gedamu ${ }^{5}$ \\ ${ }^{\prime} \mathrm{CIH}^{\mathrm{LMU}}$ Center for International Health, \\ University Hospital, LMU Munich, \\ Munich, Germany; ${ }^{2}$ Jhpiego - Ethiopia, \\ Addis Ababa, 1250, Ethiopia; ${ }^{3}$ Addis \\ Ababa University, College of Medicine \\ and Health Science, Addis Ababa, \\ Ethiopia; ${ }^{4}$ Debre-Tabor University, \\ College of Medicine and Health Science, \\ Debre-Tabor, Ethiopia; ${ }^{5}$ Jimma University, \\ Institute of Health Sciences, Jimma, \\ Ethiopia
}

\begin{abstract}
Introduction: Clinical reasoning skills are a core competency that must be taught at all levels of health-care education. In the last decade, several health professional education curricula in Ethiopia have been redesigned with the goal of improving student competence in key health-care delivery skills. Despite the fact that some academic programs followed the conventional educational strategy, a significant number of academic programs adopted a new educational strategy for curriculum development: Student-centered, Problem-based, Integrated, Community-based, Elective, and Systematic (SPICES) model. More empirical evidence, however, is required to determine whether the new curricular approach is effective in improving students' clinical reasoning. The purpose of this study is to determine whether the new educational strategy for curriculum development improves the clinical reasoning ability of midwifery students when compared to a peer institution that follows a traditional curriculum.
\end{abstract}

Methods: A comparative cross-sectional study was conducted to compare the clinical reasoning skills of midwifery students who completed the new curricular approach versus students who completed a traditional curriculum. A Script Concordance Test (SCT) was used to collect data. The mean SCT score and an independent two-sample $t$-test were calculated to see if the two groups differed significantly in terms of clinical reasoning skills in managing Post-Partum hemorrhage (PPH)

Results: A total of 77 final-year midwifery students participated (38 from the new and 39 from the traditional curriculum approach). Midwifery students who completed the new and conventional curriculum approaches had mean clinical reasoning SCT scores of $0.7(\mathrm{SD}=0.35)$ and $0.53(\mathrm{SD}=0.37)$, respectively. There was a statistically significant difference in the overall mean SCT score between the two study groups in terms of clinical reasoning skills $(p=0.008)$.

Conclusion: Our study found that the new SPICES model curricular approach is promising in fostering the development of clinical reasoning skills of Midwifery students in managing $\mathrm{PPH}$.

Keywords: clinical reasoning skills, Ethiopia, midwifery, post-partum hemorrhage, SPICES model Curriculum

\section{Introduction}

Competent professional practice requires not only affective and psychomotor skills but also sophisticated thinking, reasoning, and decision-making skills. ${ }^{1}$ Effective clinical reasoning skills improve accurate and safe diagnosis and management which prevent diagnostic errors and positively impact patient outcomes.
Correspondence: Equlinet Misganaw Tel +251913173351

Email equlinetm@gmail.com 
Conversely, poor clinical reasoning skills negatively impact effectiveness in clinical practice, quality of care and patients' experiences. ${ }^{2}$ Developing clinical reasoning skills is, therefore, a core competency expected to be acquired by all health-care professionals and must be taught at all levels of healthcare training. ${ }^{3}$

Clinical reasoning is a learned skill and requires both good educational setting and strategy to teach it. ${ }^{4}$ Clinical case presentations, case-based discussions, clinical problem-solving exercises and structured case presentation are the good settings for teaching clinical reasoning skills. A deliberate practice which includes finding opportunities for repeated practice, requesting honest feedback on performance at frequent intervals, maximizing learning from each case, reflecting on feedback and errors are also a good strategy for teaching clinical reasoning skills. ${ }^{4-7}$

In recent years, a number of studies have emerged providing evidence on the structure and content of a curriculum for fostering the development of students' clinical reasoning skills. The findings of a comprehensive evaluation of the effects of curricular approach on students' learning showed that an institution's curricular approach, practices and policies affect student clinical reasoning abilities, shape students' educational experiences and influence learning outcomes. ${ }^{8}$ The fragmented course sequencing which separates theory and practice in a traditional curriculum is considered to be one factor contributing to deficient clinical reasoning skills. ${ }^{9}$ There are well-documented weaknesses in the traditional content-based teaching approach in developing key health professional's skills. These include a lack of relevance to actual health practice and insufficient attention given to teaching communication skills, problem-solving skills, clinical reasoning skills and other social aspects of health. ${ }^{10,11}$ This leads to the existence of gaps in the competency of health workers, graduates' ability to deal effectively with real-life health situations. ${ }^{12}$

In the last decade, several health professional education curricula in Ethiopia have been redesigned with the goal of improving student competence in key health-care delivery skills. Despite the fact that some academic programs adhered to the traditional educational strategy, which is subject-centered, employs a didactic content-based teaching approach, and is distinguished by late clinical and community exposure of students, a significant number of academic programs adopted a new educational strategy for curriculum development: Student-centered, Problembased, Integrated, Community-based, Elective, and
Systematic (SPICES) model. For instance, Debre Tabor University (DTU), one of the newly established higher education institutions in Ethiopia, adopted a new educational strategy for curriculum development (SPICES) model as a remedy for the weaknesses of the conventional curriculum in the development of key health-care delivery skills including clinical reasoning skills. ${ }^{10-13}$ The new educational strategy for curriculum development incorporated developments in the field of medical education, which include: (1) competency-based curriculum design; (2) vertical and horizontal integration of the courses and clinical experiences into a conceptually meaningful structure; (3) use of innovative educational strategies like Problem Based Learning (PBL); and (4) early and longitudinal clinical and community exposure. ${ }^{14}$

More empirical evidence is needed, however, to determine whether the new educational strategy for curriculum development is effective in improving student competence, including students' clinical reasoning skills on priority health problems in the country such as postpartum hemorrhage (PPH), an obstetric emergency and the leading cause of maternal mortality, accounting for $10 \%$ of all pregnancy-related deaths in Ethiopia. ${ }^{15,16}$ Therefore, the objective of this study is to assess whether the new educational strategy for curriculum development improves clinical reasoning ability of midwifery students comparing with a peer institution that follows a conventional curriculum.

\section{Materials and Methods Study Design}

A cross-sectional study was conducted to compare the clinical reasoning skills of midwifery students from the new educational strategy for curriculum development (SPICES model) versus traditional curricular groups in the management of PPH.

\section{Study Setting and Population}

This study was conducted in Debre Tabor University and Woldia University, third generation universities located in Amhara National Regional State, Ethiopia. The study population was fourth-year midwifery students enrolled in regular baccalaureate degree program at Debre Tabor and Woldia University. Both Higher Education Institutions (HEIs) had similar student population, faculty and educational resources. The DTU midwifery department had a total of 188 students, 26 active faculty members, two clinical skill development labs, three classrooms, seven 
clinical practice sites and one library/information technology center. Similarly, WU midwifery department had 184 students, 25 active faculty members, two clinical skill development labs, three classrooms, five clinical practice sites and one library/information technology center. We invited all graduating class (final year) midwifery students in both training institutions to participate in the study. This study was conducted with the approval of Jimma University institutional review board. Survey respondents provided informed consent to participate in this study.

\section{Data Collection Methods}

Data were collected from June to July, 2017. A Script Concordance Test (SCT) was applied to assess clinical reasoning skills in the management of PPH. The SCT is a written test for assessing the reasoning skill under conditions of uncertainty. It has demonstrated favorable psychometric qualities (predictive validity of 0.721$)^{17}$ and reliability (Cronbach's alpha of 0.78 ) in research conducted across a variety of health disciplines and across the spectrum of education, from undergraduate through postgraduate to continuing professional development. ${ }^{18}$

\section{Data Collection Instrument and Quality Control}

The authors who were familiar with the purpose, target audience and content domain of the test were involved in developing items for the SCT. Careful quality-control measures were taken at whether the SCT test addresses a challenging situation or not, the inclusion of all judgment types (diagnosis, investigation, treatment, etc.) and all medical settings using quality Grid for SCT items criteria. ${ }^{19}$ Clear instructions and training were given to item writers and the quality of items was checked. The first version of the test was reviewed by five experienced midwives. Reviewers were asked to verify the relevance of questions and clarity of the wording. Low-quality questions were replaced, discarded or rewritten. The final version of the test included SCT involving 24 cases with three questions nested within each case and with testing times of 60 to 90 minutes which was administered to junior (thirdyear) and senior (fourth-year) midwifery students to assess the validity of the test. The score of the senior students was significantly greater than those of the less-trained juniors (Mean SCT score difference was 0.15, P-value 0.003). Furthermore, the mean SCT score of the expert panel members $(19.2(\mathrm{SD}=1.2)$ out of a maximum 24 points) was significantly higher than that of senior year midwifery students enrolled in both the new curriculum and the conventional approach (Mean $=16.91(\mathrm{SD}=4.5)$, $\mathrm{P}=0.003$ and $13.5(\mathrm{SD}=2.8), \mathrm{P}<0.001)$, respectively. This validated the SCT items.

\section{Administering the Test}

The SCT was developed for a paper-based selfadministered questionnaire. Because the test format was unusual for most students, the lead author provided an explanatory introduction and a few practice items to familiarize both study groups in a consistent manner.

\section{Scoring the Test}

Fifteen-panel members, all expert midwives with Master's degree in clinical midwifery and greater than five years of clinical experience, were selected to complete the test independently in order to set the response keys. Their answers were used to develop the scoring key. A maximum score of 1 was given for the response chosen by most of the experts (ie, the modal response). Other responses were given partial credit, depending on the fraction of experts choosing them. Responses not selected by experts received zero. ${ }^{20}$ Scores obtained on each question were added to obtain a total score for the test. We used an aggregate scoring method - an examinee's total score for the test was the sum of the credit obtained for each of the questions, divided by the total obtainable credit for the test. ${ }^{17-19}$ The examinee's responses to each question are compared with those of a reference panel. The panels mean thus serves as a reference value. The final score is meant to reflect how closely the examinee's judgments match with those of panel members faced with the same set of ill-defined clinical problems. ${ }^{20}$

\section{Data Analysis}

The overall mean SCT score and SD of midwifery students who went through both the new and conventional curriculum approach were calculated. An independent twosample $t$-test was used to determine whether the two groups differed significantly in each and overall mean SCT item score.

\section{Results}

A total of 77 final year midwifery students participated in this study. Of them, thirty-eight attended the new curricular approach (were from DTU) and thirty-nine attended the conventional curricular approach (were from WU). Nearly, all were under 25 years of age and males accounted for 
Table I Demographic Characteristics of Participants in the Study Based on Their Curriculum Enrollment

\begin{tabular}{|c|c|c|c|}
\hline \multicolumn{2}{|c|}{ Characteristics } & \multicolumn{2}{|c|}{ Study Group } \\
\hline & & $\begin{array}{l}\text { Midwifery Students } \\
\text { Attend New SPICES } \\
\text { Model Curricular } \\
\text { Approach }(n=38)\end{array}$ & $\begin{array}{c}\text { Midwifery } \\
\text { Students Attend } \\
\text { Conventional } \\
\text { Curricular } \\
\text { Approach }(n=39)\end{array}$ \\
\hline \multirow[t]{3}{*}{ Sex } & Male & 28 (73.7\%) & $2 \mid(53.8 \%)$ \\
\hline & Female & $10(26.3 \%)$ & $18(46.2 \%)$ \\
\hline & Total & 38 & 39 \\
\hline \multirow[t]{3}{*}{ Age } & $20-24$ & $36(94.7 \%)$ & 38 (97.4\%) \\
\hline & $25-29$ & $2(5.3 \%$ & I (2.6\%) \\
\hline & Total & 38 & 39 \\
\hline
\end{tabular}

$73 \%$ of the study participants from DTU and $53 \%$ of WU group (Table 1).

The overall mean SCT score of midwifery students who went through the new curricular approach was 0.70 (range: 0.44-0.88) while midwifery students who went through the conventional curriculum scored 0.53 (range: 0.28-0.71) (Figure 1).

A statistically significant difference in mean clinical reasoning skills SCT score was found between the two groups in 12 out of 24 SCT items (Table 2).

An independent two-sample $t$-test with equal variance assumption $(\mathrm{F}=1.09$, numerator $d f=37$, denominator $d f=$ $38, \mathrm{p}=0.78$ ) indicated a statistically significant difference in the overall (composite) mean SCT score between the two groups of study (Table 3).

\section{Discussion}

Our study is the first to generate empirical evidence and observe the outcome of different curricular approaches on midwifery students' learning outcomes in Ethiopian context.

In our study, more than one-third of midwifery students in the innovative curricular approach achieved scores above or equal to the panel mean, reflecting a mastery of knowledge in these domains that suggests a reasoning capacity compatible with autonomous professional practice.

Our result revealed that there was a statistically significant difference in the mean SCT scores between the two groups of students. In other words, the new curricular approach has a significant effect in fostering the development of midwifery students' clinical reasoning ability in managing PPH as compared to the conventional curriculum.

A high SCT score by midwifery students taught using the innovative curricular approach, therefore, indicates that an examinee interprets information pertaining to illdefined clinical problems similar to a majority of experienced midwives. ${ }^{20}$ Higher SCT scores also reflect a high degree of concordance with decisions made by the panel of experienced midwives. The high degree of concordance corresponds to the optimal use of information by students to solve authentic clinical problems and to the interconnected knowledge the students have accumulated through learning. ${ }^{17}$ The higher SCT score despite the two groups being similar in terms of their background characteristics, pre-admission GPA, and the educational environment indicate that the difference is likely to be due to the new curricular approach and educational strategies.

Our result is consistent with recent studies that have shown that curricular approach, practice, and the kinds of pedagogies institutions implement affect student learning, shape students' educational experiences, and influence learning outcomes. ${ }^{8,23}$

The curricular approaches that most likely contributed for the higher performance in clinical reasoning skills by the innovative curriculum students are the integration of courses with clinical experience, the use of innovative educational strategies like PBL and the structure of clinical experiences. Evidence from the literature suggests that integrated courses enable students to learn meaningful sets of information that are more easily retained and applied to other situations. Structuring learning in an integrated and reinforced manner can encourage the development of higher-level objectives, such as the application of knowledge, reasoning, and problem-solving skills. ${ }^{8}$ In contrast, the fragmented course sequencing which separates theory and practice in a traditional curriculum is considered to be one factor contributing to a deficient in clinical reasoning skills. ${ }^{9}$

PBL is also believed to improve the problem-solving skills of students by focusing on the development of a hypothetical-deductive reasoning process. There are also reported benefits of PBL in terms of students' ability to think critically and deal with clinical uncertainty and ambiguity. PBL has positive effects on medical competencies, particularly for improving professional and clinical diagnostic skills. Students taught in a problem-based curriculum have demonstrated improved clinical reasoning skills. $^{9,21}$ 


\section{Overall mean SCT scrore \\ SCT item \# 24: Performing bimanual compression of the... \\ SCT item \# 23: Giving Ergometrin injection \\ SCT item \# 22: Uterus not well-contracted}

SCT item \# 21: Distended abdominal and rebound...

SCT item \# 20: Cervical tears that extend into the uterus or...

SCT item \# 19:Stitching the tears

SCT item \# 18:Performing manual removal of the placenta

SCT item \# 17:Managing as atonic uterus

SCT item \# 16:Massaging the uterus

SCT item \# 15:Performing rectal examination

SCT item \# 14:Performing bimanual examination

SCT item \# 13:Performing Abdominal examination

SCT item \# 12:Laparotomy

SCT item \# 11:Digitally explore the uterus

SCT item \# 10: Examining the vagina and cervix using...

SCT item \# 9: Performing digital examination

SCT item \# 8: Palpating the uterus

SCT item \# 7 :Compressing the uterus down per abdomen

SCT item \# 6 :PPH due to Blood coagulation disorders

SCT item \# 5 :PPH due to drugs use

SCT item \# 4 :PPH due to retained tissues

SCT item \# 3 :PPH due to acute inversion of the uterus

SCT item \# 2 :PPH due to traumatic hemorrhage

SCT item \# 1: PPH due to atonicity of the uterus
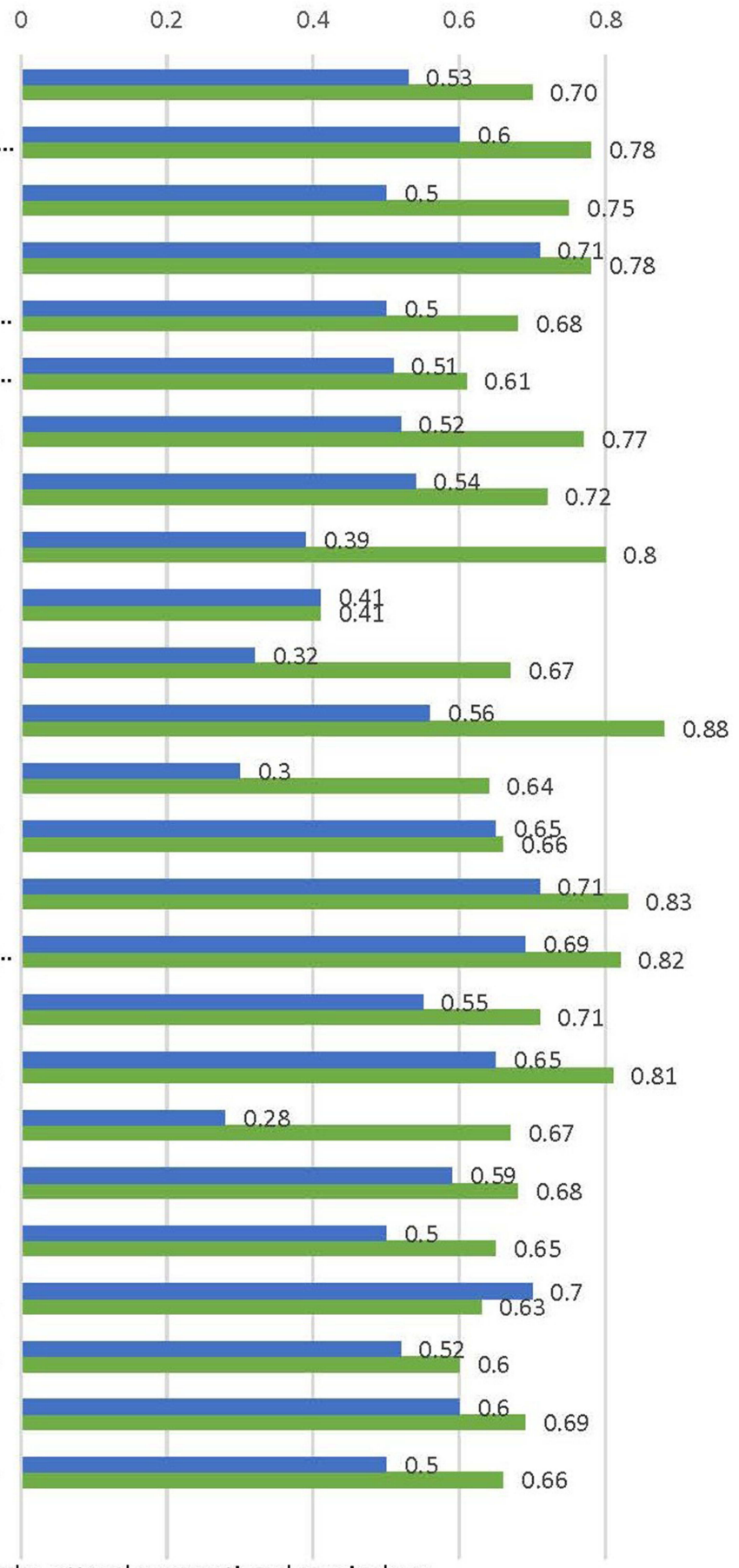

Mean SCT score of students who attend conventional curriculem

Mean SCT score of students who attend new curriculem approach

Figure I Mean clinical reasoning skills score of each SCT items by their study groups.

Another key feature of the new innovative curricular approach which offers potential for the higher performance of students in clinical reasoning skills could be the early and longitudinal structure of clinical experience. Several researchers have concluded that early and longitudinal clinical exposure is an important aspect in the development of diagnostic reasoning skills to expert level which improves with a number of clinical encounters. ${ }^{22,23}$ 
Table 2 Differences in Mean Clinical Reasoning Skills of Each SCT Item by Study Group

\begin{tabular}{|c|c|c|c|c|c|c|c|c|}
\hline $\begin{array}{l}\text { SCT } \\
\text { Item \# }\end{array}$ & Study Group & $\mathbf{N}$ & Mean & SD & $\begin{array}{c}\text { Mean } \\
\text { Difference }\end{array}$ & $\begin{array}{c}\text { t-value at } 75 \\
\text { df }\end{array}$ & P-value & $95 \% \mathrm{Cl}$ \\
\hline \multirow[t]{3}{*}{ I. } & $\begin{array}{l}\text { Attend the SPICES model curricular } \\
\text { approach }\end{array}$ & 38 & 0.60 & 0.33 & \multirow[t]{2}{*}{0.08} & \multirow[t]{2}{*}{2.20} & \multirow[t]{2}{*}{$0.03 *$} & \multirow[t]{2}{*}[0.0\mathrm{I},0.28]{} \\
\hline & Attend the conventional approach & 39 & 0.52 & 0.33 & & & & \\
\hline & Total & 77 & & & & & & \\
\hline \multirow[t]{3}{*}{2.} & $\begin{array}{l}\text { Attend the SPICES model curricular } \\
\text { approach }\end{array}$ & 38 & 0.67 & 0.39 & \multirow[t]{2}{*}{0.39} & \multirow[t]{2}{*}{4.74} & \multirow[t]{2}{*}{$0.001 *$} & \multirow[t]{2}{*}[0.19,0.48]{} \\
\hline & Attend the conventional approach & 39 & 0.28 & 0.27 & & & & \\
\hline & Total & 77 & & & & & & \\
\hline \multirow[t]{3}{*}{3.} & $\begin{array}{l}\text { Attend the SPICES model curricular } \\
\text { approach }\end{array}$ & 38 & 0.81 & 0.12 & \multirow[t]{2}{*}{0.16} & \multirow[t]{2}{*}{4.82} & \multirow[t]{2}{*}{$0.00 I^{*}$} & \multirow[t]{2}{*}[0.10,0.24]{} \\
\hline & Attend the conventional approach & 39 & 0.65 & 0.19 & & & & \\
\hline & Total & 77 & & & & & & \\
\hline \multirow[t]{3}{*}{4.} & $\begin{array}{l}\text { Attend the SPICES model curricular } \\
\text { approach }\end{array}$ & 38 & 0.71 & 0.17 & \multirow[t]{2}{*}{0.16} & \multirow[t]{2}{*}{2.66} & \multirow[t]{2}{*}{$0.009 *$} & \multirow[t]{2}{*}[0.03,0.24]{} \\
\hline & Attend the conventional approach & 39 & 0.55 & 0.27 & & & & \\
\hline & Total & 77 & & & & & & \\
\hline \multirow[t]{3}{*}{5.} & $\begin{array}{l}\text { Attend the SPICES model curricular } \\
\text { approach }\end{array}$ & 38 & 0.82 & 0.33 & \multirow[t]{2}{*}{0.13} & \multirow[t]{2}{*}{1.98} & \multirow[t]{2}{*}{$0.05^{*}$} & \multirow[t]{2}{*}[-0.00,0.27]{} \\
\hline & Attend the conventional approach & 39 & 0.69 & 0.39 & & & & \\
\hline & Total & 77 & & & & & & \\
\hline \multirow[t]{3}{*}{6.} & $\begin{array}{l}\text { Attend the SPICES model curricular } \\
\text { approach }\end{array}$ & 38 & 0.64 & 0.42 & \multirow[t]{2}{*}{0.34} & \multirow[t]{2}{*}{1.96} & \multirow[t]{2}{*}{$0.05^{*}$} & \multirow[t]{2}{*}[-0.002,0.31]{} \\
\hline & Attend the conventional approach & 39 & 0.30 & 0.26 & & & & \\
\hline & Total & 77 & & & & & & \\
\hline \multirow[t]{3}{*}{7.} & $\begin{array}{l}\text { Attend the SPICES model curricular } \\
\text { approach }\end{array}$ & 38 & 0.88 & 0.24 & 0.32 & 5.00 & $0.001 *$ & {$[0.19,0.44]$} \\
\hline & Attend the conventional approach & 39 & 0.56 & 0.36 & & & & \\
\hline & Total & 77 & & & & & & \\
\hline 8. & $\begin{array}{l}\text { Attend the SPICES model curricular } \\
\text { approach }\end{array}$ & 38 & 0.67 & 0.36 & 0.35 & 5.16 & $0.00 I^{*}$ & {$[0.21,0.48]$} \\
\hline & Attend the conventional approach & 39 & 0.32 & 0.31 & & & & \\
\hline & Total & 77 & & & & & & \\
\hline 9. & $\begin{array}{l}\text { Attend the SPICES model curricular } \\
\text { approach }\end{array}$ & 38 & 0.80 & 0.36 & $0.4 I$ & 5.28 & $0.00 I^{*}$ & {$[0.29,0.64]$} \\
\hline & Attend the conventional approach & 39 & 0.39 & 0.41 & & & & \\
\hline & Total & 77 & & & & & & \\
\hline
\end{tabular}

(Continued) 
Table 2 (Continued).

\begin{tabular}{|c|c|c|c|c|c|c|c|c|}
\hline $\begin{array}{l}\text { SCT } \\
\text { Item \# }\end{array}$ & Study Group & $\mathbf{N}$ & Mean & SD & $\begin{array}{c}\text { Mean } \\
\text { Difference }\end{array}$ & $\begin{array}{c}\text { t-value at } 75 \\
\text { df }\end{array}$ & P-value & $95 \% \mathrm{Cl}$ \\
\hline \multirow[t]{3}{*}{10.} & $\begin{array}{l}\text { Attend the SPICES model curricular } \\
\text { approach }\end{array}$ & 38 & 0.72 & 0.43 & \multirow[t]{2}{*}{0.18} & \multirow[t]{2}{*}{2.12} & \multirow[t]{2}{*}{$0.03 *$} & \multirow[t]{2}{*}[0.01,0.45]{} \\
\hline & Attend the conventional approach & 39 & 0.54 & 0.47 & & & & \\
\hline & Total & 77 & & & & & & \\
\hline \multirow[t]{3}{*}{ II. } & $\begin{array}{l}\text { Attend the SPICES model curricular } \\
\text { approach }\end{array}$ & 38 & 0.77 & 0.41 & \multirow[t]{2}{*}{0.25} & \multirow[t]{2}{*}{2.61} & \multirow[t]{2}{*}{$0.01 *$} & \multirow[t]{2}{*}[0.06,0.48]{} \\
\hline & Attend the conventional approach & 39 & 0.52 & 0.48 & & & & \\
\hline & Total & 77 & & & & & & \\
\hline \multirow[t]{3}{*}{12.} & $\begin{array}{l}\text { Attend the SPICES model curricular } \\
\text { approach }\end{array}$ & 38 & 0.75 & 0.29 & \multirow[t]{2}{*}{0.25} & \multirow[t]{2}{*}{3.26} & \multirow[t]{2}{*}{$0.001 *$} & \multirow[t]{2}{*}[0.09,0.41]{} \\
\hline & Attend the conventional approach & 39 & 0.50 & 0.36 & & & & \\
\hline & Total & 77 & & & & & & \\
\hline
\end{tabular}

Notes: *Mean difference significant at 0.05 level. Mean difference significant at 0.05 level.

Table 3 Independent Samples t-Test Comparing Composite the Mean Clinical Reasoning Skills SCT Score Between the Two Groups of Study

\begin{tabular}{|l|c|c|c|c|c|c|}
\hline Study Group & $\mathbf{N}$ & Composite Mean Score & Pooled SD & t-value at 75 df & P-value & 95\% Cl \\
\hline Attend SPICES model curriculum approach & 38 & 0.70 & 0.35 & 2.70 & $0.008 *$ & {$[0.04,0.28]$} \\
\cline { 1 - 4 } Attend conventional curriculum approach & 39 & 0.53 & 0.37 & & \\
\hline
\end{tabular}

Note: *Mean difference significant at 0.05 level.

\section{Strengths and Limitations of the Study}

This study has much strength. It generated empirical evidence on the effectiveness of innovative curriculum design in improving student learning outcomes. We selected comparable institutions in all aspects except for the curricular approach. Clinical reasoning skills were assessed using SCT, which has favorable psychometric qualities. Furthermore, the higher composite mean scores in the fourth-year than third year midwifery students show that the SCT questions supported the construct validity of the SCT scores.

This study was limited as it did not explore the contextual factors like teachers and student characteristics that may impact the findings. Also, there was no pre-test conducted and hence we would not know if the two groups had equal baseline abilities. Moreover, this study only evaluated clinical reasoning skills in managing PPH and this may not be generalizable to other clinical problems and other health-care delivery skills.

\section{Conclusion}

Our results concluded that the new curricular approach has a statistically significant effect in fostering the development of midwifery students' clinical reasoning ability in managing PPH as compared to the conventional curriculum. Hence, the innovative curricular approach promises to improve the attainment of essential competencies for health professionals. We recommend more rigorous evaluation studies to replicate these findings with other clinical problems and health-care delivery skills.

Finally, the study built additional knowledge by extending previous work on the effect of curricular approach and practice in fostering the development of students' clinical reasoning skills and influence learning outcomes particularly in resource constrained setting. ${ }^{8}$

\section{Abbreviations}

CRS, Clinical reasoning skills; DTU, Debre-Tabour University; GPA, Grade Point Average; HEIs, Higher 
Education Institution; PPH, Post-Partum hemorrhage; PBL, Problem Based Learning; SCT, Script Concordance Test; SPICES, Student centered, Problem Based, Integrated, Community based, Elective and Systematic; WU, Woldeya University.

\section{Ethics Approval}

Approval was granted by the Ethics Committee of Jimma University, Ethiopia.

\section{Consent to Participate}

Informed oral consent was obtained from all individual participants included in the study.

\section{Acknowledgments}

We are very grateful to Institute of Health Sciences, Jimma University, Ethiopia for the ethical clearance. We would also like to thank all faculties and students participated in this study for their commitment to responding for our interviews. Our gratitude also goes to supervisors and data collectors.

\section{Author Contributions}

EM contributed to the overall design, analysis and writing of the study. All authors contributed to writing and revision of the article, have agreed on the journal to which the article will be submitted, gave final approval of the version to be published, and agree to be accountable for all aspects of the work.

\section{Disclosure}

The authors report no conflicts of interest in this work

\section{References}

1. Mann KV. Theoretical perspectives in medical education: past experience and future possibilities. Med Edu. 2011;45(1):60-68. doi:10.1111/j.1365-2923.2010.03757.x

2. Loftus S. Rethinking clinical reasoning: time for a dialogical turn. Med Edu. 2012;46(12):1174-1178. doi:10.1111/j.1365-2923.2012.04353.x

3. Croskerry P. A universal model of diagnostic reasoning. Acad Med. 2009;84(8):1022-1028. doi:10.1097/ACM.0b013e3181ace703

4. Rencic J. Twelve tips for teaching expertise in clinical reasoning. Med Teach. 2011;33(11):887-892. doi:10.3109/0142159X.2011.558142

5. Elstein AS. Thinking about diagnostic thinking: a 30-year perspective. $A d v$ Health Sci Educ. 2009;14(S1):7-18. doi:10.1007/s10459-009-9184-0

6. Kassirer JP. Teaching clinical reasoning: case-based and coached. Acad Med. 2010;85(7):1118-1124. doi:10.1097/ACM.0b01 $3 \mathrm{e} 3181 \mathrm{~d} 5 \mathrm{dd} 0 \mathrm{~d}$
7. Boet S, Sharma S, Goldman J, Reeves S. Medical education research: an overview of methods. Can $J$ Anaesth. 2012;59(2):159-170. doi:10.1007/s12630-011-9635-y

8. Modi JN, Gupta P, Singh T. Teaching and assessing clinical reasoning skills clinical reasoning skills. Med Edu. 2015;52:788-790.

9. Stanczyk K, Hruskocy C, Houston C, Ligeikis K. Efficacy of problem-based learning in an integrated skills course at improving the clinical reasoning skills of dietetics students. $J$ Acad Nutr Diet. 2015;115(9):A64. doi:10.1016/j.jand.2015.06.229

10. Yigzaw T, Ayalew F, Kim YM, et al. How well does pre-service education prepare midwives for practice: competence assessment of midwifery students at the point of graduation in Ethiopia. BMC Med Educ. 2015;15(1):130. doi:10.1186/s12909-015-0410-6

11. Yigzaw T, Carr C, Stekelenburg J, et al. Using task analysis to generate evidence for strengthening midwifery education, practice, and regulation in Ethiopia. Int $J$ Womens Health. 2016;8:181. doi:10.2147/IJWH.S105046

12. Tegbar Y, Abebe F, Belay L, Assaye Y, Misganaw E, Kidane A. Quality of midwife-provided intrapartum care in Amhara Regional State. Ethiopia BMC Pregnancy Childbirth. 2017;17:261. doi:10.1186/s12884-017-1441-2

13. Goshu M, Godefay H, Bihonegn F, et al. Assessing the competence of midwives to provide care during labor, childbirth and the immediate postpartum period - a cross sectional study in Tigray region, Ethiopia. PLoS One. 2018;13(10):10. doi:10.1371/journal. pone. 0206414

14. Harden RM, Sowden S, Dunn WR. Educational strategies in curriculum development: the SPICES model. Med Edu. 1984;18 (4):284-297. doi:10.1111/j.1365-2923.1984.tb01024.x

15. Say L, Chou D, Gemmill A, et al. Global causes of maternal death: a WHO systematic analysis. Lancet Glob Health. 2014;2(6):e323e333. doi:10.1016/S2214-109X(14)70227-X

16. Brief, Based Policy. Prevention of Postpartum Hemorrhage in Rural Ethiopia; 2012.

17. Lubarsky S, Dory V, Duggan P, Gagnon R, Charlin B. Script concordance testing: from theory to practice: AMEE guide no. 75 . Med Teach. 2013;35(3):184-193. doi:10.3109/0142159X.2013.760036

18. Lubarsky S, Gagnon R, Charlin B. Scoring the script concordance test: not a black and white issue. Med Edu. 2013;47(12):1159-1161. doi:10.1111/medu. 12362

19. Lubarsky S, Charlin B, Cook DA, Chalk C, van der Vleuten CP. Script concordance testing: a review of published validity evidence. Med Edu. 2011;45(4):329-338. doi:10.1111/j.1365-2923.2010.038 63.x

20. Charlin B, Gagnon R, Lubarsky S, et al. Assessment in the context of uncertainty using the script concordance test: more meaning for scores. Teach Learn Med. 2010;22(3):180-186. doi:10.1080/ 10401334.2010.488197

21. Kong LN, Qin B, Zhou YQ, Mou SY, Gao HM. The effectiveness of problem-based learning on development of nursing students' critical thinking: a systematic review and meta-analysis. Int $J$ Nurs Stud. 2014;51(3):458-469. doi:10.1016/j.jinurstu.2013.06.009

22. Onyura B, Baker L, Cameron B, Friesen F, Leslie K. Evidence for curricular and instructional design approaches in undergraduate medical education: an umbrella review. Med Teach. 2016;38(2):150-161. doi:10.3109/0142159X.2015.1009019

23. Rochmawati E, Wiechula R. Education strategies to foster health professional students' clinical reasoning skills. Nurs Health Sci. 2010;12(2):244-250. doi:10.1111/j.1442-2018.2009.00512.x 


\section{Publish your work in this journal}

Advances in Medical Education and Practice is an international, peerreviewed, open access journal that aims to present and publish research on Medical Education covering medical, dental, nursing and allied health care professional education. The journal covers undergraduate education, postgraduate training and continuing medical education including emerging trends and innovative models linking education, research, and health care services. The manuscript management system is completely online and includes a very quick and fair peer-review system. Visit http://www.dovepress.com/testimonials.php to read real quotes from published authors. 